\title{
O SISTEMA INTERAMERICANO DE DIREITOS HUMANOS E A PROTEÇÃO DOS DIREITOS SEXUAIS E REPRODUTIVOS
}

\section{THE INTER-AMERICAN SYSTEM OF HUMAN RIGHTS AND THE PROTECTION OF SEXUAL AND REPRODUCTIVE RIGHTS}

\author{
Maiquel Angelo Dezordi Wermuth \\ Universidade Regional do Noroeste do Estado do Rio Grande do Sul (Unijuí) - (Ijuí, RS, Brasil) \\ Pâmela Copetti Ghisleni \\ Universidade Regional do Noroeste do Estado do Rio Grande do Sul (Unijuí) - (Ijuí, RS, Brasil)
}

Recebimento: 17 nov. 2016

Aceitação: 26 abr. 2017

Como citar este artigo / How to cite this article (informe a data atual de acesso / inform the current date of access):

WERMUTH, Maiquel Angelo Dezordi; GHISLENI, Pâmela Copetti. O sistema interamericano de direitos humanos e a proteção dos direitos sexuais e reprodutivos. Revista da Faculdade de Direito UFPR, Curitiba, PR, Brasil, v. 62, n. 2, p. 53 - 72, maio/ago. 2017. ISSN 2236-7284. Disponível em: <http://revistas.ufpr.br/direito/article/view/49287>. Acesso em: 28 ago. 2017. DOI: http://dx.doi.org/10.5380/rfdufpr.v62i2.49287.

\author{
Corpo meu corpo corpo \\ que tem um nariz assim uma boca \\ dois olhos \\ e um jeito certo de sorrir \\ de falar \\ que minha mãe identifica como sendo de \\ seu filho \\ que meu filho identifica \\ como sendo de seu pai \\ (Ferreira Gullar)
}

\section{RESUMO}

A contemporaneidade inaugurou novas formas de ser e estar no mundo, emprestando especial relevância às experiências concretas dos sujeitos, recusando a igualdade formal e abstrata típica da Modernidade. Nesse contexto de reconhecimento de diferenças e visibilização de demandas identitárias, o caminhar rumo à concretização de direitos humanos passa, necessariamente, pela dimensão da sexualidade e do direito de (não) reprodução. Com isso, categorias como família, casamento, sexo, afeto e desejo são reiteradamente questionadas (e ressignificadas). Quando o direito doméstico não responde adequadamente às demandas que lhe são submetidas, instituições como o Sistema Interamericano de Direitos Humanos (SIDH) revelam-se fundamentais no resgate do ideal universal de direitos humanos, atento às particularidades regionais. Portanto, este artigo trata, empregando o método hipotético-dedutivo, dos direitos sexuais e reprodutivos no direito internacional dos direitos humanos, a partir da análise de casos emblemáticos processados no âmbito do SIDH.

\section{PALAVRAS-CHAVE}

Direitos Humanos. Direito internacional. Reprodução. Sexualidade. 


\begin{abstract}
The contemporaneity inaugurated new ways of being in the world, lending special relevance to the concrete experiences of the subjects, rejecting the formal and abstract equality typical of Modernity. In this context of recognition of differences and visibility of identity demands, the journey toward the realization of human rights necessarily involves the dimension of sexuality and the right of (non) reproduction. Thus, categories such as family, marriage, sex, affection and desire are repeatedly questioned (and re-signified). When domestic law does not respond adequately to the demands submitted to it, institutions such as the Inter-American System of Human Rights (IASHR) are fundamental in the recovery of the universal ideal of human rights, paying attention to regional particularities. Therefore, this article approaches, using the hypothetical-deductive method, sexual and reproductive rights in international human rights law, based on the analysis of emblematic cases processed within the scope of the IASHR.
\end{abstract}

\title{
KEYWORDS
}

Human rights. International law. Reproduction. Sexuality.

\section{INTRODUÇÃO}

As proclamações de direitos genéricas e abstratas típicas da Modernidade, em cujo cerne gravitava a igualdade de todos perante a lei, a tutela da vida e das liberdades, foram fundamentais para a emancipação do sujeito de todas as formas de opressão, sobretudo daquelas protagonizadas pelo Estado. Mas é possível proteger, de fato, direitos humanos sem uma definição de quem (ou do quê) é o humano? Se levarmos em consideração sexo, etnia, cor e condição social, a natureza humana descorporificada e abstrata daquele indivíduo protegido sob o manto dos documentos revolucionários do século XVIII adquire uma forma bem específica: o indivíduo político universal, nesses termos, é masculino, branco e detentor da propriedade.

A contemporaneidade, não satisfeita com essa formalidade, reivindica a efetiva consolidação de direitos, catalisando as diferenças, potencializando a diversidade, fomentando que se visibilizem (e se protejam) todas as possíveis maneiras de ser e estar no mundo. Neste ínterim, o caminhar rumo à efetiva concretização dos direitos humanos passa, necessariamente, pelo reconhecimento específico de determinados direitos, os mais íntimos, os mais carnais, entre os quais se incluem os direitos sexuais e de (não) reprodução.

A sexualidade, ao introduzir em seu contexto o amor, o afeto e o romance, torna-se uma ferramenta que mede o valor social. Ou seja, projetamos em nossas experiências sexuais e amorosas um fator de reconhecimento tanto ou mais importante do que fazemos em relação às nossas possibilidades financeiras ou intelectuais, por exemplo. Isso significa que a sexualidade possibilita o reconhecimento ou a sensação de perda de valor próprio dependendo das capacidades sexuais de cada sujeito (ILLOUZ, 2016). 
Mas se nas ciências sociais ocorreram importantes avanços relativamente à sexualidade humana, no campo jurídico o debate ainda caminha a passos lentos, inclusive na seara dos direitos humanos. É possível questionar-se, então: é importante para o direito o que as pessoas sentem? A forma como desejam? Quem desejam? Arriscamo-nos a dizer que isso deveria ser o núcleo duro do fazer jurídico, tomando o cuidado, é claro, de não fazer do direito uma hermenêutica do desejo. E eis aí um paradoxo, na medida em que a sexualidade, esfera mais íntima do sujeito, rodeada de tabus, construções e desconstruções, agora se socorre no direito internacional, a mais abrangente disciplina jurídica, para ver tuteladas (autorizadas) suas diversas formas de manifestação.

Diante dessas considerações, o presente estudo trabalha basicamente com três hipóteses: (1) a sexualidade foi aventada em instrumentos normativos de direito internacional a partir da noção de direitos reprodutivos, que originou a concepção de direitos sexuais; (2) tais legislações tiveram uma preocupação muito particular com a condição feminina; (3) e em geral, têm na saúde o fio condutor de suas disposições.

Nesse sentido, o presente estudo, valendo-se do método hipotético-dedutivo, objetiva analisar como o libertar dos corpos, da palavra e dos gestos, a partir do século XX, repercutiu (ou foi omitido) no sistema jurídico, agora instigado e desafiado a regular a(s) sexualidade(s) de modo libertário. O primeiro item trata de aspectos conceituais e históricos relacionados à história da sexualidade e do corpo, ou seja, a sua aparição na cena pública não mais como pecado, mas como humano, mundano. A seguir, analisa-se a apropriação das categorias de direitos sexuais e reprodutivos pelo direito internacional. O terceiro item vai traçar o panorama institucional sobre o Sistema Interamericano de Proteção de Direitos Humanos (SIDH) para, ao final, trabalhar com três casos emblemáticos processados no âmbito do sistema e que ilustram a (im)possibilidade de emancipação de novas formas de expressão da sexualidade e também no que diz respeito à reprodução.

\section{LIBERTAR OS CORPOS E AS SEXUALIDADES}

É no corpo que a vida inscreve os eventos, traços, vivências, expectativas e frustrações de cada indivíduo, o que abrange desde as situações mais elementares e cotidianas da vida - as vacinas tomadas, o braço quebrado por causa da brincadeira de infância, a postura inadequada sustentada por anos a fio ou a exposição excessiva ao sol - até aqueles fatos mais complexos e definidores da subjetividade do ser, do que é um exemplo a sexualidade. Este ponto do estudo debruça-se, ainda que 
brevemente, sobre algumas teorizações e movimentos que antecederam o debate jurídico relativamente à sexualidade e à reprodução.

Em certa medida, a história da sexualidade se confunde com a visibilização, com a libertação do corpo. O racionalismo do século XVII inaugurou uma nova forma de pensar ao estabelecer que o acesso ao mundo se dava por meio da racionalidade. A concepção individualista de sociedade surgida a partir do século XVIII, em que pese tenha colocado o indivíduo no centro, o fez a partir da sua dimensão psíquica, relegando-se um lugar secundário ao corpo biológico. Nessa perspectiva, privilegia-se a mente em detrimento da carne. Boa parte dessa compreensão acerca do sujeito reside no legado religioso que ainda hoje interfere (ou procura fazê-lo) nas práticas sexuais.

De acordo com Richards (1993, p. 34),

[...] a cristandade foi, desde seus primórdios, uma religião negativa quanto ao sexo. Isso significa dizer que os pensadores cristãos encaravam o sexo, na melhor das hipóteses, como uma espécie de mal necessário, lamentavelmente indispensável para a reprodução humana, mas que perturbava a verdadeira vocação de uma pessoa - a busca da perfeição espiritual, que é, por definição, não sexual e transcende a carne.

Tanto é assim que na Idade Média a Igreja regulava a atividade sexual no âmbito do casamento, proibindo o ato sexual durante a gravidez, no período menstrual da mulher e quando do aleitamento, por exemplo. No século XX, contudo, Sigmund Freud (1910) rememora a temática do corpo ao introduzir novamente o ser em sua materialidade corpórea. Mais do que isso, o pai da psicanálise analisa sem rodeios inclusive a sexualidade infantil, escancarando nebulosidades até então mantidas às ocultas. Em Three Contributions to the Sexual Theory, Freud desnudou o fato de que os traços sexuais associados à perversão são, em verdade, comuns a toda a gente. Com isso, restaurou e aprofundou a temática da carne, da carcaça, do corpo orgânico e biológico, potencializando a discussão em torno daquilo que o corpo tem de mais íntimo, profano e interdito: a sexualidade (FREUD, 1910).

De fato, a partir do século XX, o corpo assume uma função extremamente relevante enquanto mediador cultural, porque ele agora se individualiza, se diferencia em relação aos demais, recebendo cada vez mais visibilidade e importância, inclusive em termos econômicos. Passa-se do "penso, logo existo” para uma espécie de “sou carne, logo existo”, pois somente o corpo permite ao sujeito agarrarse à sua própria existência. Em resumo, se antes o corpo era comunitário, social, colonizado de sentidos e signos do grupo, agora ele adquire um valor, um sentido próprio (GALIMBERTI, 2010).

Contemporaneamente, a primeira grande libertação ocorreu na palavra e nos gestos. Aquelas expressões antes sussurradas ao pé do ouvido, em voz baixa (isso quando não eram simplesmente silenciadas, tudo para não precisar verbalizar o profano, o pecado), passam a ganhar terreno a partir 
da primeira metade do século XX. Muito dessa mudança de comportamento se deve à medicalização da sociedade. "Essas evoluções linguísticas tiram a sexualidade da clandestinidade e favorecem audácias sempre maiores na alcova” (CORBIN; COURTINE; VIGARELLO, 2011, p. 133). Do mesmo modo, as carícias e demonstrações de afeto tomam outras formas, mais criativas e visíveis. O beijo começa a aparecer na literatura e também nas artes, do que é um exemplo a arte erótica do austríaco Gustav Klimt, Der Kuss ${ }^{1}$, executada entre 1907 e 1908.

Outro grande passo - e que decorre também da introdução da ideia de amor no casamento, nas relações afetivas - está no dissociar sexualidade e reprodução. Com o abortamento, as mulheres passaram a controlar cada vez mais a própria fecundidade, o que é efetivamente possibilitado com a pílula anticoncepcional. Lançada em 1960, nos Estados Unidos, a Enovid-10 permitiu que as pessoas vivessem sua sexualidade de forma mais livre. Mas, para além disso, possibilitou que mulheres, antes enclausuradas no risco iminente da gravidez, agora tivessem liberdade para escolher seu parceiro, para trair, para gozar seu desejo, ainda que de forma velada.

Não é por acaso que por volta de 1960 secundaristas e, sobretudo, universitários assumem a vanguarda e começam a teorizar sobre liberdade sexual. Alfred Kinsey lança, em 1949 e 1954, respectivamente, seus relatórios sobre as condutas sexuais masculina e feminina. Foi a partir de suas conclusões - à época tachadas de imorais e pedofílicas - que a Organização Mundial da Saúde (OMS) abandona, pouco a pouco, a ideia de homossexualidade como doença, fazendo-o definitivamente em 1990. Kinsey examinou sem pudores a masturbação, tema posteriormente analisado por Shere Hite, em 1979 e 1982, naquilo que a autora chama de profundos estudos sobre as sexualidades feminina e masculina. Por fim, é possível citar a Mística Feminina, de 1963, de Betty Friedan, e A Dialética do Sexo, de Shulamith Firestone, escrito em 1970. De fato, esses teóricos posicionam-se no sentido de não se contentar "mais em defender as experiências em nome da harmonia conjugal, mas reivindicam o direito de satisfazer sem remorso e fora de toda afetividade desejos e pulsões sexuais” (CORBIN; COURTINE; VIGARELLO, 2011, p. 144).

Essa paulatina libertação dos corpos implicou uma maior facilidade de acesso ao sexo, de modo que a prostituição perde prestígio e, em seu lugar, surgem propostas mais ousadas de voyeurismo e troca de casais. Esse novo tratamento possibilitou, do ponto de vista comercial, uma espécie de recomposição da demanda das casas de prostituição por homens, os quais preferiam

\footnotetext{
${ }^{1}$ Der Kuss é certamente uma das obras mais conhecidas de Klimt. O homem é retratado em linhas retas e retangulares, remetendo o ato de abraçar à atividade masculina. A mulher é pintada em formas arredondadas e com flores em um ato de verdadeira entrega aos braços do parceiro. "Para além do dualismo, a tela tematiza também outra importante questão psicanalítica: a relação amorosa” (PINHEIRO, 2008, p. 44).
} 
aparentar libertinagem ao extremo no lugar de clientelismo, justamente em razão de que manter relações sexuais era agora uma dinâmica facilitada. Nesse ínterim, Corbin, Courtine e Vigarello (2011) compartilham da opinião de que determinadas práticas, endossadas sob o manto da liberdade sexual, escondem uma nova forma de dominação masculina, como é o caso do voyeurismo e da troca de casais.

A troca de parceiros, a liberação aparente das regras da moral tradicional, esconde muitas vezes a mesma manipulação das mulheres. A dominação masculina sabe, portanto, como se renovar e avançar, disfarçada, sob a bandeira da liberdade sexual (CORBIN; COURTINE; VIGARELLO, 2011, p. 154).

Nesse sentido, Eva Illouz (2014), a partir de uma análise sociológica da trilogia Cinquenta Tons de Cinza ${ }^{2}$, vai dizer que as mulheres estão submetendo-se a práticas opressivas no sexo para negociar fora dele e se mobilizar do ponto de vista social, galgando melhor colocação no mercado de trabalho e na sociedade. Ou seja, o feminismo contemporâneo não se deu conta de que a luta pela liberdade sexual para as mulheres pode ser, na verdade, a consolidação de um modelo masculino de sexualidade. Portanto, a perversão, a pornografia, o sadomasoquismo emergem, hoje, como diferentes formas de expressão sexual, delineadas pelas clássicas relações de poder, em maior ou menor escala, muitas vezes para restabelecer aquele conteúdo tradicional relativamente aos papéis de gênero que se perderam por ocasião dos progressos feministas. Para Maria Filomena Gregori (2008), muito desse erotismo contemporâneo deriva do fato de que aquilo que integra a realidade do que leva à violência compõe também o cenário que leva ao prazer. Há, então, entre dor e gozo, uma linha muito tênue.

Desse breve recorte histórico, verifica-se que muitas conquistas no tocante à sexualidade estão registradas na história e são protagonizadas todos os dias. Neste ínterim, Anthony Giddens (1993) aponta que um importante progresso reside no fato de que a justificativa biológica da heterossexualidade como sendo o normal é pouco a pouco questionada (quando não destruída) nas sociedades modernas.

O fato é que o reconhecimento das diversas tendências sexuais é, mais do que nunca, um ato político de aceitação da pluralidade de estilos de vida. A sexualidade, por esse viés, é um local de luta política e de emancipação. Cria-se uma ética de vida pessoal que torna possível o respeito, a felicidade e o amor pelos outros. "A repressão sexual tem sido acima de tudo uma questão de sequestro social associado ao poder do gênero” (GIDDENS, 1993, p. 200). Daí porque o autor utiliza a ideia de intimidade como democracia.

\footnotetext{
${ }^{2}$ Na trilogia é narrada a relação de Christian Grey, homem de negócios, superpoderoso, bonito, sexy e sádico, e Anastasia Steele, jovem, estudante, virgem, que é construída e consolidada por meio das práticas sadomasoquistas. Steele é iniciada no sexo sadomasoquista por Grey, por quem se apaixona prontamente (MATTOS, 2016, p. 669-670).
} 
Diante dessa mutação do olhar sobre o corpo, que dissocia sua materialidade dos dogmas da religião e até mesmo dos costumes e da moral, é possível compreender as razões pelas quais se torna necessário legislar, no âmbito doméstico e também no cenário internacional, sobre questões relacionadas à sexualidade e à reprodução, do ponto de vista, especialmente, do reconhecimento das diferenças, concebendo a diversidade como potência libertadora. Pouco a pouco, a diversidade sexual sai do âmbito da perversão, da patologia e, portanto, do privado, e passa para o mundo social cotidiano. A questão que se coloca, portanto, é sobre como esses temas foram trazidos e narrados no debate jurídico, temática a ser discutida no ponto seguinte a partir do direito internacional, campo no qual se iniciou a visibilização, embora esparsa, dos direitos sexuais e reprodutivos.

\section{DIREITOS SEXUAIS E REPRODUTIVOS NO DIREITO INTERNACIONAL: UMA TRAJETÓRIA ENTRE O CONTROLE E A TRANSGRESSÃO}

A guinada em prol do reconhecimento de direitos sexuais e reprodutivos tem maior expressividade, a priori, nos Estados Unidos e na Europa. Na contemporaneidade, o maior catalisador dessas prerrogativas tem sido o direito internacional. O próprio termo “direitos reprodutivos”, por exemplo, foi iniciativa desse campo jurídico, adotado como forma de ampliar o significado das ações e estratégias para internacionalização da luta, no âmbito do Encontro sobre Direitos Reprodutivos, realizado em Amsterdã, em 1984. Além disso, na Conferência de Nairóbi, de 1985, fomentou-se a promoção dos direitos de reprodução enquanto uma circunstância fundamental das mulheres para uma posição justa em sociedade (ÁVILA, 1993).

Embora a temática acabe desaguando no direito de uma imensa gama de grupos minoritários, entre os quais se incluem lésbicas, gays, bissexuais, travestis, transexuais, transgêneros e andróginos, a história dos direitos sexuais e reprodutivos confunde-se, de certo modo, com a pauta feminista, na medida em que todo o debate sobre sexualidade, contracepção e aborto tem início nesse movimento de massa que ganha mais fôlego a partir da década de 1960.

A ideia de direito internacional dos direitos humanos começa a se desenvolver a partir da Declaração Universal de 1948, zeladora de uma igualdade abstrata, formal, tendo em seu bojo a tônica da proteção geral. Essa generalização, contudo, não mais bastou à compreensão dos fenômenos contemporâneos, de modo que se potencializa o debate sobre a diversidade e as diferenças, culminando em legislações que gradativamente ampliam e incorporam novos direitos a partir da perspectiva de gênero. Ambos os sistemas - o geral e o especial - não se contrariam, mas se complementam. 
Essa trajetória de reconhecimento das diferenças e fomento à diversidade inicia-se na $I$ Conferência Internacional de Direitos Humanos, no Teerã, em 1968, em que a reprodução humana foi objeto de atenção levando em consideração a situação desfavorável vivenciada por mulheres, especialmente em países em desenvolvimento, nos termos do art. 15 da Proclamação do Teerã3:

A discriminação da qual a mulher ainda segue sendo vítima em distintas regiões do mundo deve ser eliminada. O feito de que a mulher não goze dos mesmos direitos que o homem é contrário à Carta das Nações Unidas e às disposições da Declaração Universal de Direitos Humanos. A aplicação cabal da Declaração sobre a eliminação da discriminação contra a mulher é uma necessidade para o progresso da humanidade.

Importantes avanços também foram verificados a partir da I Conferência Internacional da Mulher, realizada em 1975, no México ${ }^{4}$. Nela, foi reconhecido o direito da mulher à integridade física, o que aventava as possibilidades de autonomia de decisão sobre o corpo e a maternidade. Em 1979, foi promulgada a Convenção sobre a Eliminação de Todas as Formas de Discriminação contra a Mulher $^{5}$, em cujo art. 12.1 há a previsão expressa de que os Estados-partes adotarão medidas para eliminar a discriminação contra a mulher no tocante aos cuidados médicos, para assegurar acesso a serviços médicos em igualdade de condições com os homens, inclusive no que se refere ao planejamento familiar.

Em 1980 e 1985, foram realizadas duas Conferências Mundiais sobre a Mulher, em Copenhague e Nairóbi, respectivamente. Os direitos humanos das mulheres são reconhecidos como inalienáveis em 1993, na Conferência Mundial de Direitos Humanos de Viena. Na ocasião, discutiuse a violência sexual, de modo que foram pressagiados alguns pontos importantes a serem tratados em 1994, na Conferência Internacional sobre População e Desenvolvimento, no Cairo. O Plano de Ação do Cairo ${ }^{6}$ inseriu os direitos reprodutivos no rol de direitos humanos:

Foi na Conferência Internacional sobre População e Desenvolvimento das Nações Unidas, realizada na cidade do Cairo, no Egito, de 05 a 13 de setembro de 1994, que teve por objetivo discutir temas relacionados à demografia e economia, que o termo "direitos sexuais e reprodutivos” ganhou notoriedade (SAMPAIO, 2015, p. 167).

O mencionado documento, além de introduzir tais conceitos, sinalizou para o reconhecimento específico de direitos sexuais, cujas diretrizes seriam confirmadas em 1995, na $I V$ Conferência Mundial da Mulher, realizada em Pequim. O item 96 da Plataforma de Ação de Pequim ${ }^{7}$, por exemplo, assevera que:

\footnotetext{
${ }^{3}$ Disponível em: <https://goo.gl/pJCtZT>. Acesso em: 15 nov. 2016.

${ }^{4}$ A Assembleia Geral da ONU declarou o ano de 1975 como o Ano Internacional da Mulher.

${ }^{5}$ Disponível em: <https://goo.gl/YKTY2q>. Acesso em: 15 nov. 2016.

${ }^{6}$ Disponível em: <https://goo.gl/WpzcCJ>. Acesso em: 15 nov. 2016.

${ }^{7}$ Disponível em: <https://goo.gl/ZqFpzH>. Acesso em: 15 nov. 2016.
} 
Os direitos humanos das mulheres incluem os seus direitos a ter controle sobre as questões relativas à sua sexualidade, inclusive sua saúde sexual e reprodutiva, e a decidir livremente a respeito dessas questões, livres de coerção, discriminação e violência. A igualdade entre mulheres e homens no tocante às relações sexuais e à reprodução, inclusive o pleno respeito à integridade da pessoa humana, exige o respeito mútuo, o consentimento e a responsabilidade comum pelo comportamento sexual e suas conseqüências.

Por fim, também há que ser mencionada a Convenção Interamericana para Prevenir, Punir e Erradicar a Violência contra a Mulher, realizada em 1994, na medida em que sua concretização foi especialmente relevante para o cenário latino-americano. $\mathrm{O}$ art. $2^{\circ}$ da também conhecida Convenção de Belém do Pará ${ }^{8}$ prevê expressamente que se entende "que a violência contra a mulher abrange a violência física, sexual e psicológica”, abrindo terreno para as discussões relacionadas à sexualidade.

Outros documentos relevantes destinados à proteção de direitos sexuais e reprodutivos englobam questões relacionadas à diversidade cultural e à violação de direitos das mulheres no interior da comunidade. A Declaração Conjunta para Eliminação da Mutilação Genital Feminina ${ }^{9}$, protagonizada pela Organização Mundial da Saúde (OMS) em parceria com outras importantes instituições, iniciou em 2008 um importante debate acerca da prática sob o argumento de que, entre outras coisas, não há qualquer benefício para a saúde da mulher oriundo da mutilação genital, seja lá qual for a modalidade de excisão.

Um importante marco na sociedade internacional reside na criação, por iniciativa da Assembleia Geral das Nações Unidas, da Entidade das Nações Unidas para a Igualdade de Gênero e o Empoderamento de Mulheres (ONU Mulheres), em 2010. A ONU Mulheres protagonizou uma série de declarações e convenções destinadas à proteção de direitos sexuais e reprodutivos, tendo em vista que uma das áreas de atuação da organização trata da questão do HIV e da Aids.

Essa circunstância de colonização do corpo pela medicina, especialmente no tocante ao HIV e à Aids, (re)aproximou morte e sexo, fazendo com que o foco dos principais instrumentos normativos relacionados à sexualidade seja de cunho sanitário, pragmático:

A Aids ocupa um lugar à parte na história do corpo do século XX, embora só tenha marcado as suas duas últimas décadas. Tal como a sífilis, ligada à exploração do Novo Mundo, como a cólera, associada à aceleração dos transportes e à expansão colonial, infligiu um duro desmentido a um século que pretendia eliminar as doenças infecciosas. Projetou uma sombra sobre a liberdade sexual, abalou os usos e costumes dos eruditos e dos homens comuns, e mostrou claramente a grandeza e os limites da ciência (CORBIN; COURTINE; VIGARELLO, 2011, p. 33).

\footnotetext{
${ }^{8}$ Disponível em: <https://goo.gl/lNq7v1>. Acesso em: 15 nov. 2016.

${ }^{9}$ Disponível em: <https://goo.gl/bb5qzW>. Acesso em: 15 nov. 2016.
} 
Feitas essas considerações, confirmam-se as três hipóteses iniciais da pesquisa no sentido de que (1) a sexualidade foi trazida para o debate jurídico, primeiramente, a partir da noção de direitos reprodutivos; (2) a norma efetivamente empregou maior atenção às necessidades da mulher; (3) e a saúde parece ser o foco das preocupações do legislador.

Por fim, é de se mencionar que organizações como o Comitê Latino-americano e do Caribe para a Defesa dos Direitos da Mulher (CLADEM), a Rede Latino-americana e Caribenha de Jovens pelos Direitos Sexuais e Reprodutivos e a Comissão Internacional de Direitos Humanos para Gays e Lésbicas, ao lado de outras importantes instituições, alavancaram, a partir de 2002, uma Campanha por uma Convenção Interamericana dos Direitos Sexuais e dos Direitos Reprodutivos. Em fevereiro de 2008, o grupo lançou um novo Manifesto Abreviado reafirmando a importância do documento. Entretanto, as últimas notícias disponíveis na rede relativamente à Convenção são de 2005, de modo que a medida parece não estar tendo qualquer progresso ${ }^{10}$.

Embora não exista a possibilidade (e nem a pretensão) de legislar sobre todas as questões relativas à sexualidade - esse infinito particular cheio de percalços e curvas que variam de indivíduo para indivíduo - é possível (e desejável) que se elaborem normas mais emancipadoras, que mais libertem do que limitem, que mais autorizem do que amedrontem. Quando o direito doméstico não dá conta de regular a grandeza que repousa na diversidade sexual, ou quando o faz injustamente, os sistemas regionais de proteção de direitos humanos, em alguns casos, têm proporcionado alternativas mais libertadoras. Este artigo tem por objetivo a análise específica do Sistema Interamericano de Direitos Humanos, que será realizada na sequência.

\section{SISTEMA INTERAMERICANO DE DIREITOS HUMANOS: O QUE, COMO E POR QUÊ?}

A Declaração Universal dos Direitos Humanos (DUDH) de 1948 é um verdadeiro divisor de águas no que diz respeito à tutela de direitos humanos de um ponto de vista global. Essa ideia globalizante de direitos humanos universais, contudo, é enriquecida (e por que não contestada?) pelas particularidades regionais e mecanismos próprios de cada continente. É por influência dessa nova perspectiva que surge, no âmbito da Organização dos Estados Americanos (OEA), o Sistema Interamericano de Direitos Humanos (SIDH).

“Cada sistema regional funciona, pois, em seu próprio ritmo e atento à realidade de seu continente” (TRINDADE, 2000, p. 107). O contexto latino-americano apresenta algumas

\footnotetext{
${ }^{10}$ A URL informada (<www.convencion.org.uy>) não está mais disponível na rede.
} 
particularidades que merecem atenção, pois trata-se de uma região marcada por elevado grau de exclusão e desigualdade social, no qual o imperativo da violência e da impunidade ainda é bastante presente. Então, dois fatos principais marcam o contexto latino-americano: o período dos regimes ditatoriais e a transição para os regimes democráticos, na década de 1980, na Argentina, Chile, Uruguai e Brasil (PIOVESAN, 2006).

Segundo Trindade (2000), foi com a Declaração Americana de Direitos e Deveres do Homem de 1948, responsável por conceber a ideia de direitos humanos como inerentes à pessoa humana, desenvolvendo um entendimento integral sobre direitos humanos (econômicos, sociais, culturais e políticos), e que também apresentou uma correlação importante entre direitos e deveres, que se consolidou uma base normativa que antecedeu a adoção da Convenção Americana sobre Direitos Humanos de 1969.

O Sistema Interamericano compõe-se de dois instrumentos ou regimes: um baseado na Convenção Americana ${ }^{11}$ e outro na Carta da Organização dos Estados Americanos (OEA) ${ }^{12}$. A Convenção, também denominada Pacto de San José da Costa Rica (assinada em 1969 e vigendo a partir de 1978) é o mais importante deles, e prevê um amplo leque de direitos civis e políticos, destacando-se o direito à vida, à liberdade, à resposta, à privacidade, à proteção judicial, à igualdade perante a lei, entre outros. A fim de dar efetividade ao sistema, a Convenção Americana conta com um aparato que é integrado pela Comissão Interamericana de Direitos Humanos e pela Corte Interamericana, responsável pelo monitoramento e implementação daqueles direitos que enuncia.

A Comissão Interamericana de Direitos Humanos, criada em 1959, tem competência perante todos os Estados da Convenção Americana, relativamente aos direitos humanos nela constantes, e perante todos os Estados membros da Organização dos Estados Americanos quanto aos direitos garantidos na Declaração Americana de 1948. A Comissão conta com sete membros, eleitos pela Assembleia Geral para um período de quatro anos, possibilitando-se a reeleição apenas uma vez (artigos 34 e 37 da Convenção Americana sobre Direitos Humanos).

A principal função da Comissão Interamericana é a promoção da observância e da proteção dos direitos humanos na América. Ela tem funções de conciliação, assessoria, crítica, legitimação, proteção e promoção ou fomento. A Comissão é encarregada de examinar as comunicações a elas encaminhadas e que digam respeito à violação de direitos humanos. Nesse sentido, as tarefas da

\footnotetext{
${ }^{11}$ Disponível em: <https://goo.gl/XryTUc>. Acesso em: 15 nov. 2016.

${ }^{12}$ Disponível em: <https://goo.gl/rxcekA>. Acesso em: 15 nov. 2016.
} 
Comissão são de diversas ordens e abrangem tanto a promoção quanto a proteção de direitos humanos (artigo 41 da Convenção Americana sobre Direitos Humanos).

Procedimentalmente, não há diferenças tão substanciais em relação ao que ocorre no direito interno: primeiramente, analisam-se os requisitos de admissibilidade (artigo 46) e, posteriormente, é a vez da observância do contraditório. Se não existirem motivos para arquivar a petição, a Comissão prossegue e realiza um acurado exame do assunto, investigando os fatos, se necessário. Após, a Comissão tenta alcançar uma solução amistosa entre o denunciante e o Estado e elabora um informe a ser publicado, contendo a breve exposição dos fatos e a solução.

Por outro lado, se não for alcançada uma solução amigável, a Comissão elabora um relatório conclusivo, informando se o Estado violou ou não a Convenção Americana. Esse relatório é enviado ao Estado-parte, que deve, em três meses, dar cumprimento às recomendações feitas. Dentro desse prazo, o caso deve ser solucionado pelas partes ou encaminhado à Corte Interamericana de Direitos Humanos. Se nenhuma dessas hipóteses acontecer, a Comissão, por maioria absoluta de votos, pode emitir sua própria opinião e conclusão, assinalando um prazo dentro do qual o Estado deve tomar as medidas que forem determinadas. Ao final do prazo, a Comissão decide se o Estado adotou as medidas e se publicará o informe elaborado por ocasião do relatório anual de atividades. Outra observação importante diz respeito ao fato de que somente podem submeter um caso à Corte Interamericana os Estados-partes e a Comissão Interamericana (artigo 61).

Se a Comissão considerar que o Estado não cumpriu as recomendações do informe aprovado, o caso será submetido à Corte. A partir daí, há um “quê” de juridicidade no procedimento. Todavia, o caso somente pode ser submetido à Corte se houver declaração expressa e específica do Estadoparte reconhecendo a competência da Corte para interpretação e aplicação da Convenção.

Outra cláusula facultativa da Convenção diz respeito às comunicações interestatais, caso em que um Estado-parte alega que outro cometeu violação a direito nela previsto, atendidos determinados requisitos. Por fim, diga-se que existe a possibilidade de demandar medidas cautelares perante a Comissão. Do mesmo modo, a Comissão pode solicitar à Corte a adoção de medidas provisórias para evitar danos irreparáveis (art. 74).

Conforme já assinalado, são dois os órgãos responsáveis por assegurar a implementação: a Comissão Interamericana e a Corte Interamericana. A Corte é composta por sete juízes nacionais de Estados membros da OEA. Ela tem competências consultiva (que envolve a interpretação das disposições da Convenção Americana e das disposições dos tratados relativos à proteção de direitos humanos nos Estados americanos) e contenciosa ou jurisdicional (referente à solução de controvérsias que se apresentem sobre a aplicação ou interpretação da própria Convenção). A esfera consultiva é 
mais acessível, porque qualquer membro da OEA, seja ele parte ou não da Convenção, pode solicitar o parecer da Corte. Para Piovesan (2006, p. 100), “a Corte não efetua uma interpretação estática dos direitos humanos enunciados na Convenção Americana”. Isso quer dizer que ela realiza uma interpretação dinâmica, evolutiva, de modo que se permite uma expansão de direitos.

Já no plano contencioso, a competência da Corte para o julgamento dos casos é limitada aos Estados-partes da Convenção que reconheçam tal jurisdição de forma expressa (art. 62), o que é muito criticado por alguns estudiosos da área por supostamente enfraquecer o sistema. Como se sabe, a Corte tem competência para o exame de casos que envolvam a denúncia de que um Estado violou direito que a Convenção protege. A Corte vai determinar medidas necessárias à restauração dos direitos violados ou, se for o caso, uma compensação à vítima.

Atualmente, a Corte vem enfrentando em menor medida as violações tradicionais de direitos humanos para dar lugar aos litígios envolvendo direitos coletivos, direitos de povos indígenas, direito à consulta prévia e os direitos à saúde e à seguridade social. Esse tipo de demanda requer medidas mais efetivas de reforma, de institucionalização, reconhecimento e redistribuição, o que se constitui em um verdadeiro desafio para o sistema. Ou seja, são necessárias novas e mais criativas formas de reparação, em substituição àquelas penas pecuniárias tradicionais (GARAVITO; KAUFFMAN, 2015).

O fato é que apesar das inúmeras limitações, tanto a Corte quanto a Comissão se converteram em referências importantes para a democracia, para a consolidação do estado de direito e a promoção e proteção de direitos humanos, entre os quais se incluem os direitos da sexualidade e da reprodução. O item seguinte destina-se a analisar três casos específicos que tratam diretamente da temática.

\section{A ATUAÇÃO DO SIDH NA PROTEÇÃO DOS DIREITOS SEXUAIS E REPRODUTIVOS: UMA ANÁLISE DE CASOS}

A fim de ilustrar a importância do SIDH na proteção dos direitos sexuais e reprodutivos, nesta pesquisa optou-se por analisar três casos bastante representativos sobre a temática e cuja tramitação no âmbito do direito internacional pressagia um importante progresso também no direito doméstico. 


\subsection{PELO DIREITO DE REPRODUZIR}

A petição $\mathrm{n}^{0} 12.191^{13}$ foi apresentada contra a República do Peru em 15 de junho de 1999, pelo Estudio para la Defensa de la Mujer (DEMUS), o Comité de América Latina y el Caribe para la Defensa de los Derechos Humanos de la Mujer (CLADEM), a Asociación Pro Derechos Humanos (APRODEH), o Centro Legal para Derechos Reproductivos y Políticas Públicas (CRLP) e o Centro para la Justicia y el Derecho Internacional (CEJIL), sob o argumento de que a senhora Maria Mamérita Mestanza Chávez teria sido submetida à esterilização forçada, vindo a falecer poucos dias após o procedimento, realizado em 17 de março de 1998. De acordo com o grupo peticionante, a mulher campesina, “de aproximadamente 33 anos e mãe de sete filhos”, vinha sofrendo ameaças do Centro de Salud del Distrito de La Encañada para que fizesse o procedimento de esterilização. Diante da coação exercida, a vítima foi submetida ao procedimento em 27 de março de 1998, tendo recebido alta no dia 28, em que pese o fato de ela apresentar ainda muita dor de cabeça e vômito. Por várias vezes o companheiro da senhora Chávez informou as autoridades a respeito, mas era sempre informado de que eram efeitos pós-operatórios normais. Em cinco de abril de 1998, a senhora Chávez faleceu em sua casa.

De acordo com a denúncia feita à Comissão, os fatos narrados constituem violações aos direitos previstos expressamente na Convenção de Belém do Pará e a outros da Convenção Americana de Direitos Humanos. Em resumo, sustentou-se violação, entre outros, do direito à vida, à integridade pessoal, à igualdade, à não violência, à atenção especial dada às mulheres em situação de vulnerabilidade, à saúde e à não discriminação.

Em 1999, a Comissão solicitou ao Estado peruano o envio de informações sobre o caso e, felizmente, em 28 de agosto de 2003, as partes acordaram uma solução amistosa, de modo que o Estado reconheceu as violações aos direitos da vítima, comprometendo-se a investigar a sancionar os responsáveis. Além disso, comprometeu-se a indenizar a família da vítima e a fazer alterações legislativas para favorecer a saúde reprodutiva e o planejamento familiar.

Este tipo de política governamental violadora deriva, ao fim e ao cabo, da objetificação do corpo feminino. Para mudar o comportamento reprodutivo da população no sentido do controle da maternidade, sobretudo mulheres pobres, indígenas, negras e campesinas são submetidas a procedimentos incisivos e violentos, porque é o corpo dela que gesta, é no corpo dela que se viabiliza a vida.

\footnotetext{
${ }^{13}$ Disponível em: <https://goo.gl/MeK24v>. Acesso em: 14 nov. 2016.
} 


\subsection{PELO DIREITO DE NÃO REPRODUZIR}

O caso $\mathrm{n}^{\mathrm{0}} 161-02^{14}$ foi apresentado em face do México à Comissão Interamericana de Direitos Humanos em oito de março de 2002 pelo Centro de Derechos Reproductivos (posteriormente figurando como copeticionária a Organización Alaida Foppa). As organizações alegam que a senhora Paulina del Carmen Ramírez Jacinto foi vítima de violência sexual em 31 de julho de 1999, e que na ocasião tinha 13 anos de idade. Apesar de o estupro ter sido imediatamente denunciado à Agência do Ministério Público Especializada em Delitos Sexuais e Violência Intrafamiliar, a vítima, por não ter sido devidamente orientada a respeito dos métodos de anticoncepção de emergência, engravidou do agressor. As organizações peticionantes defenderam que Paulina teria direito à realização de um aborto, com base no art. 136, II, do Código Penal de Baja California. Paulina, acompanhada de sua mãe, foi até o Ministério Público para requerer autorização para realização do aborto. O procedimento, que em um primeiro momento havia sido negado, foi autorizado em três de setembro de 1999. Em $1^{\circ}$ de outubro a menina foi internada no Hospital Geral de Mexicali, capital de Baja California. Entretanto, até oito de outubro, o aborto não foi realizado, sob os mais variados argumentos, como falta de anestesistas e ginecologistas no estabelecimento. A vítima e sua mãe novamente recorreram ao Ministério Público, que reiterou a autorização para realização do procedimento. Todavia, o Procurador de Justiça do Estado conduziu Paulina e sua mãe a um sacerdote católico, para que desistissem da prática. Em 13 de outubro, a menina retornou ao hospital e no local recebeu a visita de várias mulheres, as quais lhe mostraram, com o mesmo objetivo do sacerdote, vídeos violentos sobre práticas abortivas.

O procedimento seria definitivamente realizado no dia 15 de outubro. Entretanto, antes da sua realização, o diretor do hospital fez uma reunião com a mãe da vítima para informá-la sobre os riscos da intervenção, dentre os quais mencionou esterilidade, perfuração, hemorragia e morte. Além disso, assegurou que se a vítima morresse em decorrência do aborto, a responsabilidade seria toda da mãe. A mãe da vítima, vulnerável e fragilizada pelas informações tendenciosas prestadas pelo diretor do hospital, preferiu desistir do procedimento, de modo que o caso foi encerrado a partir de uma solução amistosa.

No que diz respeito ao aborto, destaca-se a atuação de organizações não governamentais como a Women on Waves ${ }^{15}$ e a Women on Web ${ }^{16}$. A primeira foi fundada em 1999 pela médica holandesa Rebecca Gomperts. Mãe de dois filhos, Rebecca decidiu iniciar um ativismo em favor do

\footnotetext{
${ }^{14}$ Disponível em: <https://goo.gl/NxQ1ns>. Acesso em: 8 nov. 2016.

${ }^{15}$ Disponível em: <https://goo.gl/65VXhV>. Acesso em: 2 nov. 2016.

${ }^{16}$ Disponível em: <https://goo.gl/qBOSAo>. Acesso em: 2 nov. 2016.
} 
aborto após fazer residência na África, em razão dos milhares de mulheres que viu morrerem por conta de um aborto clandestino. A ONG recebia a bordo gráficas dispostas a abortar e, uma vez em águas internacionais, um grupo de médicos atendia as mulheres de forma segura. A partir do século XXI, a ONG passou a atuar na rede mundial de computadores, e agora opera tirando dúvidas sobre aborto seguro e enviando medicamentos abortivos para os países nos quais não se tem acesso a eles.

No Brasil, o Senado Federal, por meio de sua página na rede social facebook, indagou recentemente se "as brasileiras devem perder o direito legal de interromper a gravidez resultante de estupro”. Situações como essa somente corroboram o fato de que os direitos humanos são institutos verdadeiramente frágeis e permeados por relações de poder, motivo pelo qual a luta em seu favor deve ser um exercício constante, notadamente dos grupos vulneráveis.

\subsection{PELO DIREITO DE AMAR E DESEJAR}

O último caso a ser estudado está relacionado à discriminação em razão de orientação sexual. A Comisión Colombiana de Juristas e o advogado Germán Humberto Rincón Perfetti apresentaram, em oito de fevereiro de 2005, o caso $\mathrm{n}^{\mathrm{o}} 123-05^{17}$ à CIDH, sob o argumento de que o senhor Ángel Alberto Duque foi discriminado pelo Estado colombiano por lhe ter sido negada a pensão por morte de seu companheiro, falecido em razão de complicações decorrentes da Aids, na medida em que a legislação de seguridade social não estendia o benefício aos parceiros homoafetivos. Alegaram, em resumo, violação ao direito à vida, à igualdade, à integridade física, psíquica e moral, dentre outros. A CIDH admitiu a petição e notificou as partes, publicando a decisão no Relatório Anual da Assembleia Geral da OEA.

Após tramitação do feito, em 26 de fevereiro de 2016, a Corte Interamericana de Direitos Humanos publicou uma sentença histórica, reconhecendo que a Colômbia violou os direitos de igualdade e de não discriminação. Diante dessa constatação, determinou que o Estado publicasse a sentença da Corte e seu resumo, garantisse o trâmite prioritário de eventual solicitação da vítima relativamente à pensão e, por fim, efetuasse o pagamento por danos morais e pelas custas e gastos. Trata-se de uma sentença histórica, pois é a primeira vez que a Colômbia é condenada por violar direitos de uma pessoa homossexual.

Esse caso, ao lado de outros, ilustra a importância de se visibilizar a violação de direitos sexuais e reprodutivos não somente a partir da condição feminina, embora seja verdade que boa parte

\footnotetext{
${ }^{17}$ Disponível em: <https://goo.gl/QBntv9>. Acesso em: 2 nov. 2016.
} 
das violações de direitos tem na mulher o sujeito passivo. É preciso pensar em práticas mais inclusivas e plurais, que permitam ao sujeito viver e experimentar de forma sadia e ética todas as liberdades que a sexualidade oferece.

\section{CONCLUSÃO (OU REFLEXÕES PARA NÃO CONCLUIR)}

A título de considerações finais, é possível afirmar que a construção (e consolidação) do ambiente democrático não somente tolera como também fomenta a diversidade. Verificou-se que a dissociação entre sexo e reprodução e a expansão da perspectiva de direitos sexuais para além da condição feminina permite interferir positivamente numa esfera da vida fundamental no contexto das sociedades contemporâneas. É evidente que é de extrema importância problematizar a condição feminina no que diz respeito à sexualidade, visto que as mulheres são, historicamente, o grupo subalterno no que se refere ao gênero e ao sexo. Contudo, é preciso reconhecer que a sociedade contemporânea tem novas demandas relacionadas a outras identidades que também reclamam tanta proteção jurídica quanto o fazem as mulheres, como é o caso de profissionais do sexo e transexuais, por exemplo (RIOS, 2006).

Além disso, foi possível perceber que é fundamental inserir no debate jurídico da sexualidade e da reprodução não somente a perspectiva da saúde, mas também do prazer, da liberdade, dos desejos e da diversidade, de modo que também o direito seja desafiado a reinventar-se, adequando-se à realidade humana e às inúmeras possibilidades que o ser e o estar nesse mundo oferecem.

É evidente que instrumentos normativos não possibilitarão interferências drásticas no que diz respeito às formas com as quais as pessoas se relacionam. Até mesmo porque o direito está sempre na retaguarda dos fatos, que se antecipam e o surpreendem. Não se trata de estimular a chamada inflação legislativa, mas acredita-se que normas mais libertadoras e inclusivas acenarão para novas formas de viver a sexualidade, mais plurais, livres e ao mesmo tempo responsáveis e éticas. É bem verdade que o direito se propõe a legislar muitas experiências que estão fora de seu alcance, mas quando ele começa a fazê-lo, todos aqueles grupos que estão fora do âmbito da norma começam a demandar proteção e reconhecimento.

Fomentar discussões e reflexões como a presente são fundamentais, na medida em que, apesar dos inúmeros avanços registrados relativamente aos movimentos feminista, gay, lésbico, transgênero e dos profissionais do sexo, por exemplo, ainda há um longo caminho a ser percorrido para que a inserção de tais grupos na vida social efetivamente se verifique do ponto de vista da 
cidadania, e instrumentos legais a eles relativos surjam de forma abrangente em domínios importantes, como na seara do direito internacional.

Por outro lado, não basta, para o exercício sadio da sexualidade e a fruição adequada dos direitos relativos à reprodução, a positivação de condutas, por mais permissivas que elas sejam. Por conseguinte, é fundamental (re)inserir na sexualidade um caráter ético, pois a liberdade, a iniciativa de pôr fim aos tabus relacionados ao sexo, deve caminhar passo a passo com a ética para que não se desenvolva nas relações afetivas, ainda que puramente sexuais, a mesma desigualdade de gênero até então verificada. Em outras palavras, o projeto de autoexpressão por meio da sexualidade não pode estar separado da pergunta por nossos deveres ante as outras pessoas e suas emoções.

Por fim, assinala-se que muito embora trabalhos como este tenham mais pertinência no contexto das tradições jurídicas ocidentais contemporâneas, espera-se, com certo grau de ousadia e empolgação, que esta discussão, do ponto de vista jurídico, possa ser o pontapé inicial para fomentar também a emancipação e inclusão de outros grupos vulneráveis imersos em culturas violadoras de direitos sexuais e reprodutivos.

A partir das hipóteses levantadas e verificadas, o presente texto propõe uma virada paradigmática que reconheça que: (1) a sexualidade deve ser vista como autônoma em relação à reprodução, embora as duas categorias se relacionem; (2) outros grupos socialmente vulneráveis devem ser visibilizados, ampliando-se a noção de gênero para aquilo que ela realmente se propõe a ser; (3) apesar da importância da perspectiva pragmática que relaciona saúde, sexualidade e reprodução, a legislação deve preocupar-se também com questões outras como diversidade, liberdade e respeito, relativamente a todas as formas de manifestação sexual.

\section{REFERÊNCIAS}

ÁVILA, Maria Betânia. Modernidade e cidadania reprodutiva. Revista Estudos Feministas, Rio de Janeiro, v.1, n. 2, p. 382-393, 1993. Disponível em: <https://goo.gl/qRNjGh>. Acesso em: 25 out. 2016.

CORBIN, Alain; COURTINE, Jean-Jacques; VIGARELLO, Georges. História do corpo: as mutações do olhar: o século XX. Tradução e revisão Ephraim Ferreira Alves. 4. ed. Petrópolis: Vozes, 2011.

FIRESTONE, Shulamith. La dialectica del sexo: en defensa de la revolucion feminista. Barcelona: Kairós, 1976.

FREUD, Sigmund. Three contributions to the sexual theory. Tradução A. A. Brill. Nova Iorque: The journal of nervous and mental disease publishing company, 1910. 
FRIEDAN, Betty. Mística feminina: o livro que inspirou a revolta das mulheres americanas. Rio de Janeiro: Vozes, 1971.

GALIMBERTI, Umberto. Il corpo. 20. ed. Milano: Feltrinelli, 2010.

GARAVITO, César Rodrigues; KAUFFMAN, Celeste. De las órdenes a la práctica: análisis y estrategias para el cumplimiento de las decisiones del sistema interamericano de derechos humanos. In: MAIA, Camila Barreta et al. (Org.). Desafíos del sistema interamericano de derechos humanos: nuevos tiempos, viejos retos. Bogotá: Centro de Estudios de Derecho, 2015.

GIDDENS, Anthony. A transformação da intimidade: sexualidade, amor e erotismo nas sociedades modernas. Tradução Magda Lopes. São Paulo: Ed. Unesp, 1993.

GREGORI, Maria Filomena. Limites da sexualidade: violência, gênero e erotismo. Revista de Antropologia, São Paulo, USP, 2008, v. 51, n. 2. Disponível em: <https://goo.gl/4ytf5S>. Acesso em: 28 out. 2016.

HITE, Shere. O relatório Hite sobre a sexualidade masculina. São Paulo: Difel, 1982.

HITE, Shere. O relatório Hite: um profundo estudo sobre a sexualidade feminina. 4. ed. São Paulo: Difel, 1979.

ILLOUZ, Eva. Erotismo de autoayuda: cincuenta sombras de Grey y el nuevo orden romántico. Buenos Aires: Katz, 2014.

ILLOUZ, Eva. Por qué duele el amor? Una explicación sociológica. Buenos Aires: Katz Editores, 2016.

KINSEY, Alfred et al. A conduta sexual da mulher. Rio de Janeiro: Atheneu, 1954.

KINSEY, Alfred; POMEROY, Wardell; MARTIN, Clyde. Conducta sexual del Varón. México: Editorial Interamericana, 1949.

MATTOS, Patrícia Castro. O ideal romântico do sadomasoquismo. Revista Estudos Feministas, Florianópolis, v. 24, n. 2, p. 669-672, ago. 2016. Disponível em: <https://goo.gl/cngDcy>. Acesso em: 15 nov. 2016.

PINHEIRO, Nadja Nara Barbosa. Freud e Klimt em Viena "fin-de-siècle": interfaces entre psicanálise e arte. Cógito, Salvador, v. 9. p. 42-45, 2008. Disponível em: <https://goo.gl/FQHjgA>. Acesso em: 15 nov. 2016.

PIOVESAN, Flávia. Sistema Regional Interamericano de Proteção dos Direitos Humanos. In: Direitos humanos e justiça internacional: um estudo comparativo dos sistemas regionais europeu, interamericano e africano. São Paulo: Saraiva, 2006.

RICHARDS, Jeffrey. Sexo, desvio e danação. As minorias na idade média. Tradução Marco Antonio Esteves da Rocha e Renato Aguiar. Rio de Janeiro: Jorge Zahar, 1993. 
RIOS, Roger Raupp. Para um direito democrático da sexualidade. Horizontes Antropológicos, Porto Alegre, v. 12, n. 26, p. 71-100, dez. 2006. Disponível em: <https:/goo.gl/TR6j7F>. Acesso em: 23 out. 2016.

SAMPAIO, Paula Faustino. Direitos sexuais e reprodutivos. In: COLLING, Ana Maria; TEDESCHI, Losandro Antonio (Org.). Dicionário crítico de gênero. Dourados: Ed. UFGD, 2015, p. 166-171.

TRINDADE, Antônio Augusto Cançado. O Sistema Interamericano de Direitos Humanos no limiar do novo século: recomendações para o fortalecimento de seu mecanismo de proteção. In: GOMES, Luiz Flávio; PIOVESAN, Flávia. O Sistema interamericano de proteção dos direitos humanos e o direito brasileiro. São Paulo: Ed. Revista dos Tribunais, 2000.

Maiquel Angelo Dezordi Wermuth Doutor em Direito Público pela Unisinos. Professor dos cursos de graduação em Direito da Unijuí e da Unisinos. Professor do Mestrado em Direitos Humanos da Unijuí. E-mail: madwermuth@gmail.com

Pâmela Copetti Ghisleni Mestranda em Direitos Humanos pela Unijuí. E-mail: pcghisleni@gmail.com 